completely healthy, without neurological symptoms or Kayser-Fleischer ring, and liver test results were normal. Serum caeruloplasmin 1 was slightly decreased at $95 \mathrm{mg} / 1$ (normal value in our laboratory $130-270 \mathrm{mg} / \mathrm{l}$ ), and decreased at $95 \mathrm{mg} / \mathrm{l}$ (normal value in our laboratory $130-270 \mathrm{mg} / \mathrm{l}$ ), and urine copper excretion was raised at $1.27 \mu \mathrm{mol} / 24$ th $(81 \mu \mathrm{g} / 24 \mathrm{~h}$ ) (normal
value $0.78 \mu \mathrm{mol} / 24 \mathrm{~h}(50 \mu \mathrm{g} / 24 \mathrm{~h})$ ). After a diagnostic test with ${ }^{64} \mathrm{Cu}^{2}$ a

preclinical stage of Wilson's disease was diagnosed.

He was given D-penicillamine $1 \mathrm{~g} /$ day. No side effects were observed during the first 13 months. In May 1973 he developed weakness of the right ocular muscles; in particular, ptosis was more pronounced at the end of the day. During the next 10 days the weakness became worse and left ptosis developed; no other muscles showed weakness. After edrophonium chloride $10 \mathrm{mg}$ intravenously rapid opening of both eyes was noted. Electromyography and immunological investigations were not performed. Penicillamine was withdrawn and he was given neostigmine. After six weeks he showed no symptoms of myasthenia.

Eight months later he still had no neurological symptoms. Laboratory investigations confirmed the diagnosis of Wilson's disease. An electromyogram and a laminagram of the mediastinum were normal. Though weak gram and a laminagram of the mediastinum were normal. Though weak antibodies to smooth muscles were detected in the serun

The patient was again given D-penicillamine $0.75 \mathrm{~g} /$ day. During the next
Therescenting The patient was again given D-penicillamine $0.75 \mathrm{~g} /$ day. During the next
10 months he had no side effects. Antibodies to smooth muscles were detected in May and June 1974 but not in November 1974.

The myasthenic syndrome which developed in this patient was probably induced by penicillamine, just as other autoimmune syndromes have occurred after long-term treatment with this drug. ${ }^{34}$

${ }^{1}$ Ravin, H. A., Fournal of Laboratory and Clinical Medicine, 1961, 58, 161. 2 Czlonkowska, A., et al., Acta Universitatis Carolinae, 1973, 56/57, 175.

${ }^{3}$ Boudin, G., Pepin, B., and Maqueneau, M., Nouvelle Presse Médicale, 1974, 3, 171 .

4 Walshe, J. M., Postgraduate Medical fournal, 1968, 44, Suppl. p. 6.

Department of Genetics, Psychoneurological Institute, Warsaw,

ANNA CZLONKOWSKA, M.D., Associate Professor

\section{Duodenal Obstruction due to Abdominal Aortic Aneurysm}

Patients frequently present with symptoms of upper gastrointestinal tract disease, and these sometimes suggest an obstructing lesion. Such symptoms are commonly associated with either scarring secondary to chronic peptic ulcer or hold-up due to gastric antral carcinoma. A rare cause of gastroduodenal obstruction is extrinsic pressure from abdominal aortic aneurysm. ${ }^{1}$ We describe a case and discuss previous reports.

\section{Case History}

An 80-year-old man was admitted to hospital with a four-week history of bilious vomiting, epigastric swelling, and vague upper abdominal discomfort. The vomiting had occurred only at night. A duodenal ulcer had been treated medically. He was thin and dehydrated with no clinical signs of anaemia or jaundice. The blood pressure was $140 / 90$. A $12 \times 6 \mathrm{~cm}$ smooth, slightly tender pulsatile mass was palpable in the epigastric region of the abdomen Invest, putions showed haemoglobin $17.2 \mathrm{~g} / \mathrm{dl}$, blood urea $31.5 \mathrm{mmol} / \mathrm{i}$ $(190 \mathrm{mg} / 100 \mathrm{ml})$, serum sodium $133 \mathrm{mmol} / 1$, serum potassium $3 \cdot 1 \mathrm{mmol} / 1$, serum bicarbonate $39 \mathrm{mmol} / 1$. A plain $x$-ray film of the abdomen showed a soft tissue mass in the upper abdomen and a calcified aortic aneurysm on the lateral view. A gastrografin meal showed that the body of the stomach was raised over a large aneurysm. The proximal duodenum was dilated as far as the distal second part. On turning the patient on to his side pressure became apparent mainly at the duodenojejunal flexure.

Intravenous fluids were started, and his electrolytes reverted to normal, the blood urea falling to $5.8 \mathrm{mmol} / 1(35 \mathrm{mg} / 100 \mathrm{ml})$. At laparatomy the presence of an aortic aneurysm, $6 \mathrm{~cm}$ wide, was confirmed. In view of his age and relatively frail condition radical resection was rejected in favour of anterior gastrojejunostomy. Postoperative recovery was uneventful with complete relief of symptoms.

\section{Discussion}

Osler $^{2}$ first described duodenal obstruction as a feature of abdominal aortic aneurysm. There have been seven similar cases. ${ }^{3}$ These patients invariably complained of nausea, vomiting, and abdominal pain. Five of the patients admitted to weight loss and several were emaciated. The duration of symptoms was variable, ranging from days or weeks to 11 years. An abdominal mass was palpable. Duodenal obstruction was confirmed in all but two cases by contrast radiology. The site of obstruction was the third part of the duodenum except for one patient where there was hold-up at the pylorus. Two patients had symptoms severe enough to cause electrolyte imbalance due to vomiting. In another a phytobezoar was found at necropsy in the obstructed duodenum. ${ }^{4}$ Four patients were treated by simple bypass: posterior gastrojejunostomy in two, anterior gastrojejunostomy in one, and isoperistaltic duodenojejunostomy in the fourth case. One patient underwent resection of his aneurysm but died ten hours later. ${ }^{5}$ A further patient died before surgery could be performed. ${ }^{4}$ Two survived bypass procedures and their symptoms were relieved.

Our patient conformed to the usual pattern. Interestingly, vomiting occurred only at night but was sufficiently severe to cause dehydration, alkalosis, and hypokalaemia. He was treated by anterior gastrojejunostomy and this was very successful. It had also proved effective in two previous cases. The only patient to undergo radical surgery died immediately afterwards. A palliative bypass procedure thus appears to be satisfactory and the surgeon should not be tempted to perform major surgery if the patient's fitness is doubtful.

I should like to thank Mr. J. Bla'e and Dr. R. Courtenay-Evans for permission to report this case and for their advice in preparation of the manuscript.

${ }^{1}$ Eastcott, H. H. G., Arterial Surgery, 2nd edn. London, Pitman Medical, 1973

2 Osler, W., Lancet, 1905, 2, 1089.

3 Sondheimer, F. K., and Steinberg, C. L., American Fournal of Roentgenology, 1964, 92, 1110.

4 Panoro, V. A., and Melzer, M. J., New York fournal of Medicine, 1970,

$70,673$.
5 Desiderio, V. C., Kownacki, V., and Wilson, W. L., Gastroenterology, $1959,37,766$.

Mayday Hospital, Mayday Road, Thornton Heath, Surrey, CR4 7YE H. M. ADAIR, F.R.c.s., Surgical Registrar

\section{Side Effects due to Treatment of Hypertension with Prazosin}

Prazosin is a new antihypertensive agent which has recently become available. Its antihypertensive action is said to be due to phosphodiesterase inhibition in arteriolar smooth muscle. Early reports ${ }^{1}$ indicated that postural hypotension should not be a major problem, and only a few patients had had other side effects. This apparent freedom from side effects would make it very useful, particularly in elderly patients. We have used this drug in a total of eight patients, two (nos 1 and 2) in hospital, and six in general practice. Both hospital cases and five others developed severe side effects after starting Prazosin.

\section{Case Histories}

All the patients had normal renal function on the basis of blood urea concentrations. The table summarises the relevant details for each patient. Severe
hypotension occurred in patients 1 and 7 , and symptoms of postural hypohypotension occurred in patients 1 and 7, and symptoms of postural hypo3 and 7 , and patient 5 experienced palpitations. Other symptoms were weakness, light headedness, dizziness, and diarrhoea.

\section{Discussion}

We believe, from our experience with relatively few patients, that side effects due to Prazosin may be more common and on occasions much more severe than previously reported. Other reports of side effects have led to the Committee on Safety of Medicines to issue an Adverse Reaction Notice. ${ }^{2}$ In view of the combination of hypotension and appreciable vasodilatation in patient 1 we postulate that hypotension is due to rapid onset of alpha-receptor blockade. It is now recommended that the first dose of Prazosin should be given just before the patient goes to bed at night. We think that the severity of hypotension can be so great that even this method of starting therapy could be 